\title{
No limite da oposição: uma análise crítica da interpretação chomskiana do conceito de forma em Humboldt
}

Fernanda Cizescki*

\begin{abstract}
Resumo: Tendo em vista que Chomsky usa o conceito de forma presente em Humboldt como um dos alicerces de sua teoria, o objetivo deste artigo é o de analisar detalhadamente um possível estreitamento das ideias humboldtianas causado pela interpretação chomskiana que teria provocado, em alguma medida, um distanciamento entre o gerativismo e outras teorias. Por isso, a hipótese deste trabalho é que Humboldt, devido a abrangência de suas ideias, já havia, embrionariamente, apresentado algumas das soluções que acabaram sendo propostas por Newmeyer (1998) em sua análise sobre a convergência entre funcionalismo e gerativismo.
\end{abstract}

Palavras-chave: Forma da língua; Humboldt; Chomsky.

Abstract: Given the fact that Chomsky uses the concept of form developed in Humboldt's work as one of the basis of his theory, this paper aims at analyzing in detail a possible narrowing of humboltian ideas caused by the chomskyan interpretation which would have caused, to same extent, a distance between generative theory and other theories. Therefore, the hypothesis is that Humboldt, because the scope of his ideas, had presented, embryonically, some of the solutions that have just been proposed by Newmeyer (1998) in his analysis of the convergence of functionalism and generativism.

Keywords: Language form; Humboldt; Chomsky.

\section{Introdução}

Após muito tempo de apagamento de seus estudos linguísticos, Humboldt (1767-1835) e parte de suas ideias sobre forma e criatividade da língua foram trazidos a público pelo americano Noam Chomsky. Nas palavras de Weedwood (2002):

Sua influência, bem como a distinção entre forma interna e externa, também pode ser sentida no pensamento de Ferdinand de Saussure (1957-1913). Mas suas implicações plenas provavelmente só viriam a ser percebidas e tornadas precisas em meados do século $\mathrm{XX}$, quando o linguista americano Noam Chomsky reenfatizou-a e fez dela uma das noções básicas da gramática gerativa. (p.109)

* Doutoranda do Programa de Pós-graduação em Linguística da UFSC. 
Obviamente, isso não que dizer que não se tenha falado sobre Humboldt antes de Chomsky - a própria Weedwood ainda cita o filólogo Heymann Steinthal e o psicólogo Wilhelm Wundt - mas, sem dúvida, foi devido a Chomsky que o mundo linguístico passou a ouvir falar mais do autor prussiano. Um exemplo disso é que até Chomsky ter lançado seu "Current Issues in Linguistic Theory" em 1964, aparentemente, não havia tradução de "Über die Verschiedenheit des menschlichen Sprachbaues und ihren Einfluss auf die geistige Entwicklung des Menschengeschlechtes"1. Este é o livro linguístico mais importante de Humboldt, conhecido como "Introdução ao Kawi". Chomsky cita, em seu "Cartesian Linguistics", de 1965, que uma tradução estava sendo organizada naquele ano. Até então, consta nas referências de Chomsky somente um facsímile da obra.

As principais análises que Chomsky fez das ideias de Humboldt estão nos dois livros supracitados. Por isso, eles serão centrais na discussão estabelecida aqui. Nesses livros, são discutidos alguns dos aspectos centrais presentes no "Introdução ao Kawi”, mas cabe dizer que no Cartesian Linguistics há também comentários sobre o livro "Os limites da ação do estado" que, por questões de foco deste trabalho, não serão abordados. Outros livros de Chomsky serão eventualmente mencionados, mas não analisados, pois menções a Humboldt se resumem a citações da frase sobre a língua fazer "uso infinito de meios finitos".

Humboldt aparece mais nesses livros iniciais de Chomsky, possivelmente, porque eles surgiram num período de formação e de constituição filosófica da teoria gerativa chomskiana, no qual o americano recorreu aos mais diversos trabalhos sobre linguagem para estabelecer e validar suas ideias sobre linguagem. Assim, ele contextualizou sua teoria como continuadora de uma tradição cartesiana já existente, cuja teorização sobre o aspecto criativo (e gerativo) da linguagem teria seu maior expoente em Humboldt. Por isso, é nesse período que as ideias humboldtianas exerceram sua mais forte influência, tanto como base da obra de Chomsky, quanto como exemplo daquilo que foi chamado de "modelo gerativo transformacional".

\footnotetext{
1 "Sobre a diversidade da construção linguística humana e seu impacto sobre o desenvolvimento mental da humanidade". A tradução do título foi extraída da introdução à edição brasileira: "Humboldt: Linguagem, Literatura e Bildung", pois não há publicação desse livro no Brasil.
} 
Porém, ao se distanciar da perspectiva de Chomsky e começar a ler Humboldt, entra-se em contato com a diversidade e amplitude das ideias humboldtianas. Isso torna quase inevitável colocar sob questionamento até que ponto a interpretação feita por Chomsky condiz com o exposto por Humboldt, ou, para além disso, parece essencial indagar se ele realmente capturou e quis utilizar as ideias humboldtianas em toda sua abrangência. Partindo disso, vê-se que, em contraposição a esse fato positivo, da maior valorização das ideias de Humboldt, está o aspecto não tão positivo de essas ideias terem sido, em grande parte, conhecidas pelo viés da interpretação chomskiana.

Devido a isso, o objetivo aqui é o de analisar detalhadamente um possível estreitamento das ideias humboldtianas causado pela interpretação chomskiana. Esta, por sua vez, teria se espalhado pela linguística contemporânea, causando parte das divergências existentes entre a gramática gerativa e outras teorias.

No intuito de cumprir este objetivo, a teoria escolhida para servir como contraponto é o funcionalismo. A escolha foi feita devido à relevância de um livro chamado "Language Form and Language Function", de Newmeyer, no qual o autor aborda exatamente os pontos em que as teorias gerativa e funcionalista, aparentemente divergentes em sua totalidade, não se excluem, mas sim, convergem.

A partir da leitura desse livro, a hipótese que surge é a de ser possível ver nos escritos de Humboldt, mesmo que embrionariamente, a resolução de algumas dessas divergências. Para além disso, acredita-se que essas resoluções coincidem parcialmente com os aspectos levantados por Newmeyer, principalmente no concernente ao posicionamento de Humboldt em relação à influência do uso efetivo da linguagem na forma.

No intuito de discutir a hipótese supracitada, há de se comparar a caracterização do conceito de forma da língua presente em Humboldt e em Chomsky. Para tanto, serão levantados os pontos em que a leitura deste diverge, ou não dá conta, do existente na obra daquele. Como Chomsky faz diversas citações a Humboldt ao longo de sua obra linguística, mas centra sua discussão sobre a forma no seu “Current Issues”, esse será o livro mais enfocado ao longo da presente discussão.

Mesmo sabendo que a noção de criatividade acompanha a de forma, pretende-se aprofundar mais a discussão sobre forma para abordar, em linhas gerais, o tema presente 
em "Language Form and Language Function" e discutir a pertinência da hipótese esboçada anteriormente.

Dessa maneira, pretende-se, ao mesmo tempo, problematizar a exposição que Chomsky fez das ideias de Humboldt, discutir a repercussão dessa leitura na linguística moderna e ratificar a originalidade e atualidade da obra humboldtiana.

\section{Construção do conceito de Forma da Língua em Humboldt}

A mais conhecida obra linguística de Humboldt foi publicada postumamente e pode ser chamada, como já citado, de "Introdução ao Kawi". Nela, Humboldt dedica um capítulo ao esclarecimento do que entende por forma e qual seu papel no estudo das línguas. Como esse assunto se constitui de bastantes detalhes, faz-se interessante percorrer, mesmo que rapidamente, a noção de língua, bem como o contexto em que ela aparece na referida obra. Isso facilitará a compreensão e a discussão feita adiante.

Deve-se ter em mente que, para Humboldt, a verdadeira definição de linguagem precisa ser contemplada naquilo visto por ele como cerne: a constante transição, ou melhor, a atividade (Energeia). Partindo disso, o primeiro ponto a ser ressaltado é: em Humboldt a língua é vista como um organismo cuja origem está entrelaçada com o cerne da ação intelectual, pois ambos são indicotomizáveis e interdependentes. Por isso, "não se deve ver a língua como mero produto morto, mas, muito pelo contrário, como um ato produtivo.” (2006, p.95). Ora, se, como propõe Humboldt, "só é possível conceber a existência do intelecto em atividade e como atividade" (2006, p.101), poder-se-ia estender essa consideração à língua que, se originando e caminhando junto com ele, seria também vista em e como atividade. Talvez por isso, ela crie a si mesma todo o tempo, fato este que embasa a ideia de a língua ser atividade (Energeia) e não obra acabada (Ergon).

Vale ressaltar que esse organismo caminha juntamente com a nação e, por isso, "é o sopro, a própria alma da nação, surgindo sempre no mesmo passo que ela." (2006, p.03). Então, a nação se cria com a língua que, por sua vez, se cria com a atividade do intelecto. Como essa atividade abarca tanto características mais objetivas, quanto as mais subjetivas, pode-se concluir que a criação da nação, da língua e do indivíduo se dá 
ao mesmo tempo e reciprocamente. Por meio dessa junção, torna-se possível entender e abstrair a triangulação entre linguagem, homem e universo, presente na obra humboldtiana. Isso porque, o próprio sujeito se constitui ao ter uma linguagem que, segundo Heidermann, transcende em complexidade o mundo dos fenômenos e "não é apenas um instrumento utilitário do dia-a-dia. Sua função é facilitar o posicionamento epistemológico do indivíduo.” (p. XXXII - XXXIII). Essa linguagem, ao mesmo tempo, participa da formação do indivíduo e se constitui nele.

Além disso, não se pode deixar de levar em consideração o posicionamento de Humboldt em relação aos opostos, já que isso também influencia diretamente a noção de língua. Observa-se ao longo da obra que, para ele, os opostos são conectados um ao outro e se produzem mutuamente, pois

a combinação dos mais elementares conceitos estimula todo o tecido das categorias do pensamento, posto que o positivo exige e produz o negativo, a parte o todo, a unidade a multiplicidade, o efeito a causa, a realidade a possibilidade $\mathrm{e}$ a necessidade, o condicionado $\mathrm{o}$ incondicionado, uma dimensão do espaço-tempo a outra, cada grau de sentimento um outro que lhe seja mais próximo, então, tão logo se consiga expressar com clareza e definição a mais simples combinação de idéias, também no que diz respeito à plenitude das palavras faz-se presente $\mathrm{o}$ todo da língua. Tudo que se pronuncia forma $\mathrm{o}$ impronunciado ou prepara-o. (2006, p.27)

Dessa forma, a língua é vista como um sistema no qual "todos os detalhes existem através de outros, e tudo somente através da força única que perpassa o todo.” (2006, p.25).

Essa característica de Humboldt traz consigo uma ampla gama de consequências relacionadas à constante transição entre opostos, como no caso das dicotomias entre universal/particular; objetivo/subjetivo. Um exemplo disso, vinculado à língua, é o fato de Humboldt usar a ideia da existência de um "esforço permanentemente reiterado do espírito de capacitar o som articulado para a expressão do pensamento" (2006, p.99) para definir, ao mesmo tempo: ato individual de fala, língua - que seria a totalidade desses atos - e atividade do intelecto.

Ora, tem-se aqui, na verdade, o reflexo da tentativa de não reduzir sua teoria a mais um trabalho dicotomizador que privilegiaria ou a questão universal, ou a particular. Ao contrário disso, Humboldt parece estar sempre buscando a integração dos 
opostos. Estes, segundo ele, só existem porque a ação do pensamento faz eles existirem (2006, p.11). Nesse caso, então, vê-se justamente uma definição que se pode aplicar tanto a algo particular, como um ato de fala individual, quanto a algo mais amplo, como a língua. Seja ela entendida como uma língua específica ou como uma língua qualquer, no sentido de uma língua em geral.

Conhecendo-se com um pouco mais de clareza a multiplicidade da visão de Humboldt sobre a língua, torna-se mais fácil adentrar a ideia de forma da língua que está diretamente conectada à atividade do intelecto. Esta "está sempre dirigida para algo já dado, de modo que não cria livremente, sim, transforma” (2006, p.103) e ocorre de forma "constante e uniforme, pois a força intelectual que a exerce mantém-se a mesma, variando apenas dentro de limites rígidos e poucos amplos." (2006, p.103). Sua finalidade é o entendimento. Partindo disso,

aquilo que a atividade do intelecto (de elevar o som articulado até o nível da expressão do pensamento) contém de constante e uniforme, se for apreendido tão completamente quanto possível em todas as suas conexões e for representado sistematicamente - constitui a forma da língua. (2006, p.103-105)

Humboldt ressalta que embora essa definição apareça como uma "abstração moldada pela ciência" (2006, p.105), ela não deve ser vista como algo sem existência real, pois ela é na verdade, um impulso "uno e cheio de vida" (2006, p. 105). Porém, ele somente é visto em suas consequências e não em sua totalidade, isso faz com que seja necessário sintetizá-lo num conceito morto.

Por fim, acercando-se da constante via de mão dupla humboldtiana entre universal e particular, a forma da língua e a definição de atividade do intelecto estão presentes, ao mesmo tempo, nos aspectos mais particulares e nos mais gerais da língua. Porém, segundo ele, a forma é mais perceptível ao se ver a língua em geral do que ao se observar seus elementos isoladamente. Essa característica torna extremamente complicado sistematizá-la e vê-la em todos os elementos da língua.

De acordo com Humboldt, devido à dificuldade gerada pelo fato de não se perceber a forma língua nos elementos isolados, para observá-la, seria necessário utilizar-se de uma visão mais geral. Porém, isso faria ressaltar a individualidade, de modo que "a descrição da forma de qualquer uma delas, no sentido aqui apresentado, 
não pode ser nunca realizada na íntegra, mas apenas até um certo grau, que no entanto é suficiente para alcançar a visão geral do todo" (2006, p. 109). Todavia, esse ainda é, segundo ele, o melhor caminho para não se incutir no erro de deixar de fora coisas que fazem parte do organismo, respeitando, assim, a abrangência e a diversidade da língua.

Com base nisso, pode-se afirmar ser a forma da língua algo constante que faz parte de uma língua. Esta, vinculada à atividade do intelecto, cria-se (ou transforma-se) constantemente, de acordo com algumas regras. Embora essas leis sejam constantes, variam “dentro de limites rígidos e pouco amplos” (2006, p.103). É justamente o efeito e a interpretação feitos por Chomsky desse conceito que guiam à próxima sessão.

\section{A interpretação chomskiana e seu reflexo na gramática gerativa}

O objetivo desta sessão é apresentar e problematizar a interpretação chomskiana do conceito de forma presente em Humboldt, principalmente, como já citado, no "Current Issues in Linguistic Theory" de 1964 (doravante CILT). Algumas considerações serão feitas partindo de "Cartesian Linguistics" (doravante CL) de 1965. A escolha se deu, pois essa é a fase inicial de constituição filosófica e consolidação do modelo gerativo como proposto por Chomsky. As obras posteriores serão mencionadas, mas não analisadas detalhadamente pelo simples fato de a análise mais profunda feita por Chomsky constar nessas duas obras.

Sabe-se que os primeiros trabalhos de Chomsky têm por característica a crítica tanto ao behaviorismo, quanto ao estruturalismo: o seu CILT é um exemplo disso. No livro, Chomsky apresenta e busca mostrar as diferenças entre dois modelos conflitantes de gramática gerativa: o taxonômico (classificação sistemática) e o transformacional; o primeiro é um abandono da linguística estrutural e o segundo é mais próximo à gramática tradicional. Saussure, por exemplo, se encaixaria no modelo taxonômico, pois relaciona a classificação sistemática com a ideia gerativa de Langue. Enquanto a gramática de Port-Royal estaria relacionada ao modelo transformacional, pelo fato de haver uma estrutura subjacente que forneceria a interpretação semântica e outra para a interpretação fonológica.

Com vistas a mostrar a distância entre sua teoria e aquilo que ele chamou de linguística taxonômica, Chomsky recorreu a semelhanças com a gramática tradicional e 
afirmou ser um continuador de uma ideia já anteriormente desenvolvida pelos gramáticos de Port-Royal e por Humboldt, a saber: a existência de uma estrutura subjacente na língua ${ }^{2}$.

Para embasar a discussão, Chomsky julga interessante considerar como essas noções aparecem na gramática tradicional, na linguística clássica e na taxonômica. Por isso, seu objetivo principal, no primeiro capítulo - "Goals of Linguistic Theory" - é conceitualizar e contextualizar a gramática gerativa, tentando situar sua perspectiva entre a gramática tradicional e a visão humboldtiana da língua. Para tanto, ele desenvolve sua discussão partindo do conceito de criatividade e comparando a visão humboldtiana de língua, vista como atividade, com a de Whitney (1872), para quem, segundo Chomsky, a língua não passaria de um conjunto de palavra e frases.

Já num primeiro momento, é interessante saber que, para Chomsky, "there is one respect in which this work [CILT] diverges in principle from the Humbolddtian framework." (1964, p.20). E esse ponto de divergência está relacionado à visão sobre semântica presente em Humboldt. Isso conduz a leitura a uma perspectiva na qual esse parece ser o único que precisa ser exposto como divergente. Aqui, abre-se espaço ao primeiro dos questionamentos a serem, quiçá, respondidos ao longo do texto: na análise chomskiana, teriam sido abordados todos os aspectos das ideias humboldtianas a ponto de se estabelecer com segurança a afirmação anterior?

A obra de Humboldt (Introdução ao Kawi) é apresentada no CILT, em sua maior parte, por citações do autor. Nessas citações, os textos mais recorrentes são "Forma das línguas" e "Natureza e constituição da linguagem em geral”, com algumas passagens do “Conexión del sonido con la forma interior", em que está a famosa frase sobre a língua "fazer uso infinito de meios finitos"3 (1990, p.131).

Os comentários de Chomsky são, basicamente, resumos das idéias de Humboldt, os quais visam situar as idéias do autor prussiano em relação àquilo que Chomsky

\footnotetext{
${ }^{2}$ Cabe relembrar que, nesse período, a idéia da gramática gerativa era a de uma representação da competência por meio de um sistema de regras que se constitui de três componentes: sintático (central); fonético e semântico (interpretativos). O componente sintático gera uma estrutura abstrata que é convertida em representação fonética pelo componente fonético (Superficial Structure) e recebe uma interpretação semântica do componente semântico (Deep Structure).

${ }^{3}$ Não há tradução desse texto para o português, a fonte utilizada aqui é a tradução paraa o Espanhol de Ana Agud.
} 
chamou de gramática gerativa. Na verdade, das cinco páginas dedicadas a Humboldt, cerca de metade constitui-se de citações em alemão, sem tradução ${ }^{4}$. Isso ocorre, pois, aparentemente, não havia tradução da obra nessa época: nas referências há somente um fac-símile.

De posse disso, o intuito é analisar de perto a interpretação feita por Chomsky (1964). Segundo ele, para Humboldt, a forma da língua é o que há de subjacente e invariável em cada ato linguístico e dá significado a ele: "the essence of each language is what Humboldt designates as its form" (1964, p.17). Por isso, as primeiras citações são para caracterizar que: "the notion of "form" as "generative process" underlies Humboldt's entire account of the nature of language and of the use and acquisition of language, and constitutes perhaps his most original and fruitful contribution to linguistic theory" (1964, p.17)

Mesmo antes de recorrer às citações, parece essencial observar mais detalhadamente a seguinte afirmação do excerto: "A noção de forma como um "processo gerativo" fundamenta todas as considerações de Humboldt sobre a natureza da linguagem, seu uso e aquisição". Essa colocação de "forma como um processo gerativo" torna viáveis mais questionamentos sobre quais seriam as implicações dessa afirmação de Chomsky: até que ponto a forma é vista como processo em Humboldt? A forma da língua tem a capacidade de criar (ou transformar) no ideário do prussiano?

Ora, sabendo-se que, para Humboldt, ela não é estanque, talvez se pudesse pensar em um processo. Porém, para ele, apesar de precisar ser colocada num conceito, aparentemente morto, ela é um "impulso uno e cheio de vida". Impulso, aqui, deve ser entendido como algo "absolutamente individual mediante o qual uma nação faz valer, através da língua, seu pensamento e sentimento." (2006, p.105). É certo que a idéia de um fio condutor, ou de algo que impulsiona as línguas e as caracteriza em sua especificidade, aproxima-se da proposta chomskiana, mas não inteiramente: em sua gramática ele está interessado na competência (ideal e universal) e esse fato excluiria a questão da individualidade das línguas e a influência que ela exerce na forma geral.

\footnotetext{
${ }^{4}$ As traduções do alemão utilizadas nesse artigo vem da edição bilíngue organizada por Werner e Markus e da tradução para o espanhol do feita por Ana Agud. Por isso, todas as citações correspondentes às citações feitas por Chomsky no CILT, estão traduzidas ao longo do texto.

${ }^{5}$ Tradução minha.
} 
Com as leituras de Humboldt é possível perceber esse impulso como um propulsor da atividade do intelecto ${ }^{6}$, constituído de leis que regem o processo gerativo. No entanto, quem cria (transforma) é a língua, pois ela se cria indefinidamente. A forma, da maneira como é encarada nesse trabalho, é como uma identidade linguística, um apanhado de regras constantes, quase invariáveis que fundamentam e dão suporte à existência da língua específica e, ao mesmo tempo, caracterizam certa universalidade:

A língua não pode ser vista como uma substância espalhada, na sua totalidade perceptível ou aos poucos comunicável, e sim como algo que se cria a si mesmo eternamente, onde as leis de produção são definidas, porém, a abrangência e de certo modo também o tipo do produto permanecem por completo indeterminadas. $(2006, \mathrm{p} .139)$

As passagens selecionadas por Chomsky, em sua maioria, guiam o leitor para uma interpretação que contempla a noção de forma como algo estanque, embora ele mesmo tenha falado em forma como um processo responsável pela geração da língua. Além disso, não há referência à questão do papel da individualidade, do subjetivismo e das características particulares das línguas.

Inclusive, em seu "Knowledge of Language" de 1986, ele justifica a presença dessa questão da individualidade como uma característica do período Romântico. Ora, por mais que ele esteja correto em sua afirmação, isso não é motivo para não haver menção significativa a essas características ao longo do CILT. Afinal, a noção humboldtiana de forma é impregnada por essa influência romântica, a ponto de isso se tornar essencial, inclusive no estudo da língua como um todo. De qualquer forma, vale registrar uma passagem de Humboldt que remete a isso: "Aliás nenhum dado factual ou individual é excluído pelo conceito de forma.” (2006, p. 113)

Ao contrário, a forma, em Chomsky, acaba sendo reduzida as suas características gerais. Além disso, apesar de a seguinte passagem ser citada, parece não ter sido incorporada nas idéias do americano:

\footnotetext{
${ }^{6}$ Pensa-se aqui num propulsor continuo, num impulso que se reitera no intuito de garantir a constante atividade inerente à língua e ao intelecto.
} 
É somente quando galgamos desde os componentes dispersos até chegar àquela unidade que verdadeiramente conseguimos um conceito da língua em si, uma vez que, sem proceder assim, claramente corremos o risco de não entender nem mesmo a verdadeira particularidade daqueles componentes, quanto mais suas reais conexões. (HUMBOLDT, 2006, 113)

Humboldt diz que o certo seria estudar indo da substância em direção a forma para se estabelecer com mais segurança "um conceito da língua em si”. Porém, Chomsky deixa clara sua opção na seguinte passagem:

A generative grammar, in the sense sketched above, is an attempt to represent, in a precise manner, certain aspects of the Form of language, and a particular theory of generative grammar is an attempt to specify those aspects of form that are a commom human possession - in humboldtian terms, one might identify this latter with the underlying general form of all language. (1964, p.20)

Chega-se aqui àquilo caracterizado na introdução como um estreitamento provocado pelo americano: ele optou por não contemplar a característica da teoria humboldtiana de tratar das dicotomias universal/particular; objetivo/subjetivo sem hierarquizá-las. Aparentemente, isso pode parecer um simples recorte feito na teoria de Humboldt, porém, o que deve ser pensado são as consequências desse recorte para as afirmações de Chomsky sobre ter as ideias humboldtianas como base.

Talvez a maior característica desse estreitamento seja a ideia de forma ter adquirido a imagem de algo ideal, perfeito e imutável, como é a competência que, em Chomsky, opõe-se ao desempenho. Como consequência, questões que para Humboldt fazem parte da essência viva da língua, em Chomsky se tornaram problemas de desempenho sem serventia para os estudos linguísticos.

Ainda parece interessante resgatar um comentário do próprio Chomsky em seu CL sobre o CILT, de acordo com ele, o CILT é "um estudo da linguística geral de Humboldt" (CHOMSKY, 1965, p. 50). Todavia, parece mais condizente vê-lo como uma breve discussão daquilo que, presente no "Introdução ao Kawi”, serve aos propósitos de formação da gramática gerativa da maneira como é entendida por Chomsky. Afinal, características do período romântico presentes no vínculo entre nação, língua e indivíduo não fazem parte da análise chomskiana e sequer são abordadas no livro. 
Obviamente, o americano tem o direito de escrever sua teoria da maneira como entender mais apropriada, mas o fato de ele afirmar que "there is one respect in which this work diverges in principle from the Humboldtian framework." (CHOMSKY, 1964, p.20) não pode passar despercebido. Afinal, Humboldt diz: "tão prodigiosa é a individualização dentro da uniformidade geral da língua que podemos dizer com igual acerto que a humanidade inteira possui em verdade uma única língua e que cada pessoa tem uma língua em particular." $(2006,107)$. Não parece que seja possível tratar somente de um desses aspectos sem isso implicar uma divergência com a estrutura do ideário humboldtiano.

Além disso, há ainda alguns detalhes interessantes que também não são citados por Chomsky: em Humboldt, a forma abarca questões sobre a história da língua, pode ter uma produção equivocada (ao contrário do ideal de forma chomskiano) e, mais que isso,

Uma parte sustancial de la estructura de los períodos y de la construcción del discurso no se explica, sin embargo, por recurso a las leyes, sino que depende del que habla o escribe em cada caso. A la lengua le cabe entonces el mérito de ofrecer liberdad e riqueza de medios a la diversidad de los modos de expressión, por más que con frecuencia su labor se limite a proporcionar la possibilidad de crear tales modos por uno mismo. (1990, p.124)

Ora, essas leis são aquilo que constitui a forma da língua em Humboldt. Por isso, parece estar ainda mais distante a interpretação de Chomsky da proposta de humboldtiana. Esse fato exposto na citação é justamente o elo que conecta a presente análise à hipótese baseada na obra de Newmeyer, como é melhor explicitado abaixo.

\section{Newmeyer e a discussão entre forma e função}

O objetivo aqui, não é fazer uma análise extensa do livro de Newmeyer, nem abordar todos os tópicos presentes em sua obra. Ao contrário, busca-se um contraponto baseado numa das idéias que ele apresenta ao argumentar que no debate entre formalismo e funcionalismo não há somente divergências, como se poderia supor num primeiro olhar.

Cabe dizer que o autor é formalista e o livro surgiu depois de ele ter lido diversos materiais sobre o funcionalismo e ter se surpreendido "by the wealth of 
interesting generalizations (...) found in the best functionalist writings" (1998, p.xi). A partir daí, ele acabou formulando o livro, no intuito de problematizar as mais típicas considerações que permeiam o dito debate.

Os tópicos discutidos por ele ao longo do livro são apresentados no primeiro capítulo por meio de um diálogo hipotético entre os personagens Chris Funk e Sandy Form. Eles discutem, em linhas gerais, os pontos divergentes entre as teorias. Algumas das afirmações que eles fazem cabem na discussão feita aqui, pois entram em questões que, como se viu acima, estavam presentes em Humboldt, mas não em Chomsky.

Para tanto, são usadas como exemplos algumas das frases do diálogo. A certa altura da conversa, Funk diz "the functions of language - including that of conveying meaning - have left their mark on language structure to a degree that it's hopeless to think that you can understand anything about this structure without working out how it's grounded functionally." (NEWMEYER, 1998, p. 2).

Em contraposição, é interessante transcrever duas afirmações de Form também: "we generativists are on the right track when we characterize form without worrying about function" (p.02) ou então: "GB and Minimalist principles are too grammarspecific, too abstract, and too removed from any function to be a response, even indirectly, to those fuctions." (p.4).

Partindo de questões como essas, Newmeyer diz que seu argumento se baseará em discutir a complementaridade das duas visões, pois "formalists are absolutely correct in their commitment to characterizing form independently of meaning and function. But at the same time, functionalists are right that meaning and function can help to shape form." (p.6)

Tomando essa afirmação de Newmeyer, sem entrar na análise e argumentos por ele propostos, pode-se tornar a Humboldt e perceber que lá já havia o embrião da ideia de que não só a forma deve ser levada em consideração, pois a "a língua propriamente dita reside no ato de sua efetiva enunciação" (HUMBOLDT, 2006, p.101):

A bem da verdade,é somente a fala seqüencial que deve ser considerada como prioritária e substancial em todos os estudos que pretendem penetrar na essência viva da língua. A quebra em palavras e regras nada mais é que obra mal feita e morta, produzida pela prática desmembradora da ciência. 
Une-se a isso o contexto da citação sobre a língua "fazer uso infinito de meios finitos" que não é citado em Chomsky:

La lengua se enfrenta em el sentido más genuíno con um domínio infinito y sin fronteras, el conjunto de todo lo pensable. Eso obliga a hacer um uso infinito de médios finitos, cosa que le es posible em virtud de la identidad de la fueza que engendralas ideas y el lenguaje. Pero esto supone al mismo tiempo que la lengua ejerce su efeccto em dos direcciones distintas: primero sale de sí y se introduce em lo que dice em cada caso, y luego retorna desde ahí a las fuerzas que la han engendrado. Ambos efectos están siempre modificándose el uno al outro dentro de cada lengua em virtud del método observado em ella, y por eso deben tomarse juntos a la hora de exponer $\mathrm{u}$ enjuiciar tal método. (HUMBOLDT, 1990, p.131)

Essa passagem ratifica a existência, em Humboldt, da ideia de que a forma é influenciada pela efetivação da língua, pois ela "primero sale de sí y se introduce em lo que dice em cada caso, y luego retorna desde ahi a las fuerzas que la han engendrado. Ambos efectos están siempre modificándose el uno al outro" (p.131). Essa conclusão do autor vem, obviamente, da já citada transição entre opostos. Esta, sendo deixada de lado por Chomsky, provocou uma caracterização ideal da forma que não cabe em Humboldt, pois "es cierto también que em la parte puramente ideal de la lengua, em la que ésta depende exclusivamentee da les conexiones del endendimiento, se hallan divergencias, mas se deben casi siempre a combinaciones incorrectas o deficientes" (p.116).

Certamente, isso se encaixa mais com a ideia precursora de uma forma não estanque que pode ser influenciada pela produção efetiva, como pretende Newmeyer.

\section{Conclusões}

Apesar de não ser um autor amplamente citado e lido, a atualidade e originalidade das ideias de Humboldt é algo geralmente ressaltado por autores que dele se ocuparam ${ }^{7}$. Porém, para além do comumente citado, viu-se como interessante tratar da abrangência de sua obra não só no que concerne a tê-lo como o precursor de idéias e correntes, mas sim, como um sujeito que, além de influenciar teorias pode, devido à

\footnotetext{
${ }^{7}$ Pode-se citar Weedwood, Chomsky.
} 
amplitude de seus escritos, tê-las transcendido, antes mesmo de elas terem sido sistematizadas.

Percebeu-se que Chomsky, apesar de dizer ter sido influenciado por Humboldt e ter nele muitos dos princípios de sua teoria - inclusive e principalmente o conceito de forma - tratou a teoria de Humboldt unilateralmente, sem levar em conta as implicações de se atribuir reciprocidade entre o universal e o particular.

Dessa maneira, analisaram-se duas afirmações humboldtianas, a saber: a de que a forma da língua é aquilo que há de constante na atividade do espírito e a de que a língua se constitui como tal somente no ato do proferimento. Por fim, partindo de um esboço da ideia de Newmeyer sobre a complementaridade entre funcionalismo e gerativismo, intentou-se ratificar a presença de uma possibilidade de conexão entre essas correntes em Humboldt, que teria sido apagada da linguística justamente pelo estreitamento provocado por Chomsky.

\section{Referências}

CHOMSKY, Noam. Aspects of the Theory of Syntax. Massachusetts: MIT, 1965.

Current Issues in Linguistic Theory. Paris: Mouton,1964.

Diálogos com Mitsou Ronat. São Paulo: Cultrix, 1977.

. Estruturas Sintácticas. Lisboa: Edições 70, 1957.

Knowledge of Language. New York: Praeger, 1986.

Lingüística Cartesiana. Madrid: Gredos, 1969.

Linguagem e Pensamento. Rio de Janeiro: Vozes, 1971

.Three Models for the description of language. I.R.E, Transactions on information Theory, Vol. IT-2, p.113-124, 1956.

DILLINGER, Mike; PALÁCIO, Adair. Lingüística gerativa: Desenvolvimento e Perspectivas uma Entrevista com Noam Chomsky. D.E.L.T.A., vol. 13. $\mathrm{n}^{\mathrm{o}}$ especial. 1997. 
HEIDERMANN, Werner; WEININGER, Markus.(Orgs.). Humboldt: Linguagem, Literatura e Bildung. Florianópolis: UFSC, 2006.

HUMBOLDT, Wilhelm von. Sobre a natureza da linguagem em geral. (in: Humboldt: Linguagem, Literatura e Bildung). Tradução de Paulo Sampaio de Oliveira. UFSC, 2006.

HUMBOLDT, Wilhelm von. Forma das Línguas (in: Humboldt: Linguagem, Literatura e Bildung). Tradução de Karin Volobuef. UFSC, 2006.

HUMBOLDT, Wilhelm von. Natureza e constituição da linguagem. (in: Humboldt: Linguagem, Literatura e Bildung). Tradução de Markus J. Weininger. UFSC, 2006.

. Sobre la diversidad de la estructura del lenguaje humano y su influencia sobre el desarrollo espiritual de la humanidad. Tradução de Ana Agud. Barcelona: Anthropos, 1990.

NEWMEYER, Frederick. Language Form and Language Function. Massachusetts: MIT, 1998.

1996.

. Generative Linguistics: a historical perspective. London: Routledge,

PINKER, Steven. The Language instinct: How the mind creates language. New York: Harper Perennial, 2007a.

Viking, 2007b.

The Stuff of Thought: Language as a window into human nature. New York:

WEEDWOOD, B. História concisa da lingüística. Tradução de Marcos Bagno. São Paulo: Parábola Editorial, 2002.

Artigo recebido em: 31.03 .2012

Artigo aprovado em: 01.05.2012 